\title{
Bronchial Variation: Anatomical Abnormality May Predispose Chronic Obstructive Pulmonary
}

\section{Disease}

This article was published in the following Dove Press journal:

International Journal of Chronic Obstructive Pulmonary Disease

\author{
Xian Wen Sun ${ }^{1,2}$ \\ Ying Ni Lin ${ }^{1,2}$ \\ Yong Jie Ding ${ }^{1,2}$ \\ Shi Qi Li ${ }^{1,2}$ \\ Hong Peng $\mathrm{Li}^{1,2}$ \\ Qing Yun $\mathrm{Li}^{1,2}$
}

'Department of Respiratory and Critical Care Medicine, Ruijin Hospital, Shanghai Jiao Tong University School of Medicine, Shanghai, People's Republic of China;

${ }^{2}$ Institute of Respiratory Medicine,

Shanghai Jiao Tong University School of

Medicine, Shanghai, People's Republic of China
Correspondence: Qing Yun Li

Department of Respiratory and Critical Care Medicine, Ruijin Hospital, Shanghai jiao Tong University School of Medicine, No. 197, Ruijin Er Road, Shanghai, 200025, People's Republic of China Tel +86-2I-643I4I 62

Email liqingyun68@hotmail.com

\begin{abstract}
Noxious particulate matter in the air is a primary cause of chronic obstructive pulmonary disease (COPD). The bronchial tree acts to filter these materials in the air and preserve the integrity of the bronchi. Accumulating evidence has demonstrated that smoking and air pollutants are the most prominent risk factors of COPD. Bifurcations in the airway may act as deposition sites for the retention of inhaled particles, however, little is known concerning the impacts of abnormalities of the bronchial anatomy in the pathogenesis of COPD. Studies have reported significant associations between bronchial variations and the symptoms in COPD. In particular, it has been shown that bronchial variations in the central airway tree may contribute to the development of COPD. In this review, we identified three common types of bronchial variation that were used to formulate a unifying hypothesis to explain how bronchial variations contribute to the development of COPD. We also investigated the current evidence for the involvement of specific genes including fibroblast growth factor $10(\mathrm{FgflO})$ and bone morphogenetic protein $4(\mathrm{Bmp} 4)$ in the formation of bronchial variation. Finally, we highlight novel assessment strategies and opportunities for future research of bronchial variations and genetic susceptibility in COPD and comorbidities. Our data strongly highlight the role of bronchial variations in the development, complications, and acute exacerbation of COPD.
\end{abstract}

Keywords: chronic obstructive pulmonary disease, bronchial variation, fibroblast growth factor 10 , bone morphogenetic protein 4

\section{Introduction}

Chronic obstructive pulmonary disease (COPD) is a leading cause of death and in 2015 showed an increasing prevalence of 174.5 million cases worldwide. ${ }^{1}$ The inhalation of toxic particles and smoking are the primary risk factors for COPD. However, only 10-20\% of chronic heavy cigarette smokers develop symptomatic COPD. Whilst several factors have been associated with COPD including asthma, genetic inheritance, maternal smoking during pregnancy, low birth weight and lower respiratory tract infections during childhood, ${ }^{2,3}$ the precise risks of COPD remain to be fully understood. Also, bronchial anatomy abnormalities may be involved in the pathogenesis of COPD.

In 2018, Smith and colleagues reported that one-quarter of the normal population have variations in bronchial anatomy that may contribute to the development and progression of chronic respiratory diseases, particularly COPD. These variations are also associated with Fgf10 mutations. ${ }^{4}$ The findings provide new insights 
into the anatomical and genetic basis of COPD. In this review, we discuss the role of bronchial variations in the pathogenesis and comorbidities of COPD.

\section{Bronchial Variation Subtypes and Identification}

Bronchial variations present of absent, displaced, or accessory origin in the bronchi and can occur either simultaneously or successively. The three most common subtypes of bronchial variations are tracheal bronchus, accessory cardiac bronchus, and bridging bronchus (Table 1). ${ }^{5}$ Tracheal bronchus was first described by Sandifort et al in 1785 and originates from the trachea towards the upper lobes, as mentioned in a paper by Aktas et al. ${ }^{6}$ Accessory cardiac bronchus was first defined by Brock et al in 1946 and is short or long diverticulum arising medially from the main bronchus or the right bronchus intermedius. ${ }^{7}$ Finally, bridging bronchus was first described by Gonzalez-Crusssi et al in 1976 and appears as variations originating from the left main bronchus that cross over to the right bronchus. ${ }^{8}$ Uncommon bronchial variations include tracheal diverticulum and bronchial isomerism. Clinically, bronchial variations are typically combined with other congenital deformities such as tracheal stenosis, cardiovascular malformations, and Down syndrome.

Multi-detector CT (320-slices) with 3D reconstruction and multi-planar reconstruction (MPR) can be used to measure the lengths and diameters of the variant bronchi. ${ }^{9}$ Magnetic resonance imaging (MRI) with surface shaded display (SSD), and virtual endoscopy (VE) can be used to observe the transaxial, coronal and sagittal sections of the bronchi. These approaches display the bronchial performance and protrusion outside the lumen and can detect deviations within $10 \% .{ }^{10} 3 \mathrm{D} \mathrm{O}_{2}$-enhanced MRI has strong capabilities for both ventilation and perfusion assessment that can be used to improve the classification of clinical stages in COPD. ${ }^{11}$ Endobronchial optical coherence tomography (EB-OCT) is useful in the assessment of small airway disorders (diameter $<2 \mathrm{~mm}$, 9th generation bronchi) and in COPD as it can display the mucosal, submucosal, smooth muscle, and cartilage layers of the airway structure. The mean luminal diameter, inner luminal area and the airway wall area of the 3rd-6th generation bronchi are known to correlate with forced expiratory volume in one second $\left(\mathrm{FEV}_{1}\right)$ in percent of predicted $\left(\mathrm{FEV}_{1} \%\right)$ $(\mathrm{r}=0.731, p<0.001) .{ }^{12}$ Also, EB-OCT shows a more accurate and comprehensive assessment of small airway remodeling than traditional CT assessment. Recently, artificial intelligence (AI) has been used to quantify emphysema automatically and this approach may also be applicable to identify bronchial variations in future research. ${ }^{13}$

\section{Bronchial Variation and COPD Development}

COPD is characterized by partially irreversible lung airflow obstruction and has several major risk factors including cigarette smoking. Smith and colleagues first reported

Table I Three Common Bronchial Variation Subtypes and Clinical Abnormalities

\begin{tabular}{|c|c|c|c|c|}
\hline Sites & Origin & Develop & Variation Subtypes & Clinical Abnormalities \\
\hline $\begin{array}{l}\text { Trachea } \\
\text { Bronchus }\end{array}$ & Trachea & Directs to the UL & $\begin{array}{l}\text { a) Displaced (a branch of the RUL } \\
\text { missing) } \\
\text { b) rudimentary (tracheal diverticulum) } \\
\text { c) supernumerary (normal trifurcation in } \\
\text { RUL) } \\
\text { d) anomalous RUL bronchus (duplication } \\
\text { of RUL) }\end{array}$ & $\begin{array}{l}\text { Tracheal stenosis, bronchostenosis, Down } \\
\text { syndrome, VACTERL syndrome (vertebral } \\
\text { variations, anal atresia, cardiac } \\
\text { abnormalities, tracheoesophageal fistula and } \\
\text { or esophageal atresia, renal agenesis and } \\
\text { dysplasia, limb defects) }\end{array}$ \\
\hline $\begin{array}{l}\text { Accessory } \\
\text { Cardiac } \\
\text { Bronchus }\end{array}$ & $\begin{array}{l}\text { Right main } \\
\text { bronchus, } \\
\text { intermediate } \\
\text { bronchus }\end{array}$ & $\begin{array}{l}\text { Towards the } \\
\text { mediastinum, parallel } \\
\text { to the RMB toward } \\
\text { pericardium }\end{array}$ & $\begin{array}{l}\text { a) Short (blind-ending diverticulum) } \\
\text { b) intermediate (branching with alveolar) } \\
\text { c) terminal sprigs (undeveloped lobulus) }\end{array}$ & $\begin{array}{l}\text { Bronchial fistula, diverticula, adenoid recess } \\
\text { and tumor }\end{array}$ \\
\hline $\begin{array}{l}\text { Bridging } \\
\text { Bronchus }\end{array}$ & $\begin{array}{l}\text { Left main } \\
\text { bronchus }\end{array}$ & $\begin{array}{l}\text { Crossing over the } \\
\text { mediastinum }\end{array}$ & $\begin{array}{l}\text { a) Subtype I (normal trachea bifurcating } \\
\text { into RB) } \\
\text { b) subtype } 2 \text { (absent or short } \\
\text { diverticulum of RB) }\end{array}$ & $\begin{array}{l}\text { Hypoplastic lungs, left PA sling, imperforate } \\
\text { anus, absent coccyx, horseshoe kidney and } \\
\text { cardiovascular malformations }\end{array}$ \\
\hline
\end{tabular}

Note: Data from Wooten et al. ${ }^{5}$

Abbreviations: PA, pulmonary artery; RUL, right upper lobe; RB, right bronchus; RMB, right middle bronchus; UL, upper lobes. 
accessory subsuperior bronchial variations associated with an increased risk of COPD prevalence $(\mathrm{OR}=1.64,95 \% \mathrm{CI}$ : 1.18-2.29, $p=0.004)$. The patients with accessory subsuperior variation tended to have an increased incidence of emphysema (apparent diffusion coefficients 0.19, 95\% CI: 0.07-0.30). ${ }^{4}$

Bronchial variation may contribute to COPD in several ways. Firstly, airway bifurcations may provide deposition sites in which inhaled particles can aggregate. At displaced or accessory bronchi, goblet cell proliferation may be destroyed by the abnormal distribution of mucosa glands and cilia. The disordered movement of cilia promotes the dysfunction of mucociliary clearance (MCC). Consequently, impaired MCC allows bacterial pathogens and toxic particles to gain a foothold in the lower respiratory tract which increases mucus secretion and decreases lung clearance. The colonization of pathogens and particles contributes to chronic airway inflammation by altering the host adaptive immune response via TLR3 triggering of the IFNs pathways and bronchopulmonary damage. ${ }^{14}$ The loss of the mucus barrier covering the bronchial epithelium during frequent airway infection is associated with the acute exacerbation of COPD (AECOPD). Thus, the bifurcation anomalies induce more bacterial and particle deposits resulting in the release of chemokines and cytokines; both of which serve to promote local inflammation and contribute to COPD and AECOPD. ${ }^{15}$ Secondly, the lengths and diameters of airways can affect the development of COPD. Smith found that the cumulative length of the absent right lower lobe medial-basal bronchial variation was $29.0 \%$ longer but with $6.9 \%$ smaller subsegments calibers compared to normal bronchi. In contrast, the accessory right lower lobe sub-superior bronchial variation presented $7.3 \%$ shorter length and $26.3 \%$ larger calibers with a higher percentage of emphysema. ${ }^{4}$ The observed decreased bronchial diameters contribute to airflow limitation and airway remodeling which are the major causes of dyspnea in COPD patients. Thirdly, most patients who are born with bronchial variations are asymptomatic but suffer from respiratory tract infections throughout life particularly adenovirus bronchiolitis, pneumonia and bronchiectasis. Based on these observations, the extent of pathological changes in the different bronchial variations are specific to individual COPD patients.

It is well known that early exposure to either particulate matter or pathogens promotes abnormal changes during lung development. Continuous exposure to dust from birth to 28 days postnatally increases the expression of transforming growth factor (TGF)- $\beta 1$ and matrix metalloprotease (MMP)-9. ${ }^{16}$ Pregnant rats maintained at under $11.5 \% \mathrm{O}_{2}$ from gestation show greater anatomical variation in airway lumen area $(0.205 \pm 0.009$ vs $0.187 \pm 0.002$, $\sqrt{ }$ area $\left./ \mathrm{P}_{\mathrm{bm}}\right)$ and have a heterogeneous distribution of airway lumen caliber in adulthood. ${ }^{17}$ Also, respiratory tract infections are an important factor in the growth and development of children. Respiratory syncytial virus (RSV) can spread across the placenta from the respiratory tract of the mother to the fetus. ${ }^{18}$ Childhood exposure to RSV is a risk factor for adult RSV illness (OR=2.38; 95\% CI: 1.03-5.51). ${ }^{19}$ RSV infection and pneumonia during infancy $(\mathrm{OR}=3.59$; 95\% CI: 1.41-9.14) and nitrogen oxide exposure during at less than 1 year of age $(\mathrm{OR}=3.08$; 95\% CI: 1.11-8.51) are independent risk factors for the irreversible airflow limitation. ${ }^{20}$ This may be due to epigenetic alterations in gene regulation, modulation of the immune response, aberrant molecular signaling, and growth factors involved in lung development.

The increased risk of COPD at 53 years of age is related to the early accelerated decline in $\mathrm{FEV}_{1} \mathrm{Z}$-scores $(\mathrm{OR}=35.0,95 \%$ CI: 19.5-64.0), persistently low $\mathrm{FEV}_{1} \mathrm{z}$-scores $(\mathrm{OR}=9.5,95 \%$ CI: 4.5-20.6) and below average $\mathrm{FEV}_{1}$ z-scores $(\mathrm{OR}=3.7$, 95\% CI: 1.9-6.9) in children. These factors contribute to $75 \%$ of COPD burden and make patients susceptible to damage from smoking, particle matter or pathogens. ${ }^{21}$ Patients with bronchial variations may be born with impaired lung function, or experience respiratory tract infection at birth, in childhood and adolescence, with sustained and accelerated airflow limitations. These individuals suffer from COPD at an early age under the combined effects of genetic and environmental factors (Figure 1). These alterations are more likely to occur during early life and even in utero suggesting that there is a susceptibility window during which genetics can disrupt normal bronchial development. ${ }^{22,23}$

\section{Genetic Variation and Bronchial Variation in COPD FgflO and Bmp4 Participate in the Development of Bronchial Variation}

To elucidate the effects of bronchial variation in COPD, we recognize that the bronchial variations originate during tracheobronchial embryonic development. The patterns of bronchial architecture develop based on the reciprocal interactions and morphological changes between the airway epithelium and the mesenchyme if environmental exposure is not taken into account. The 


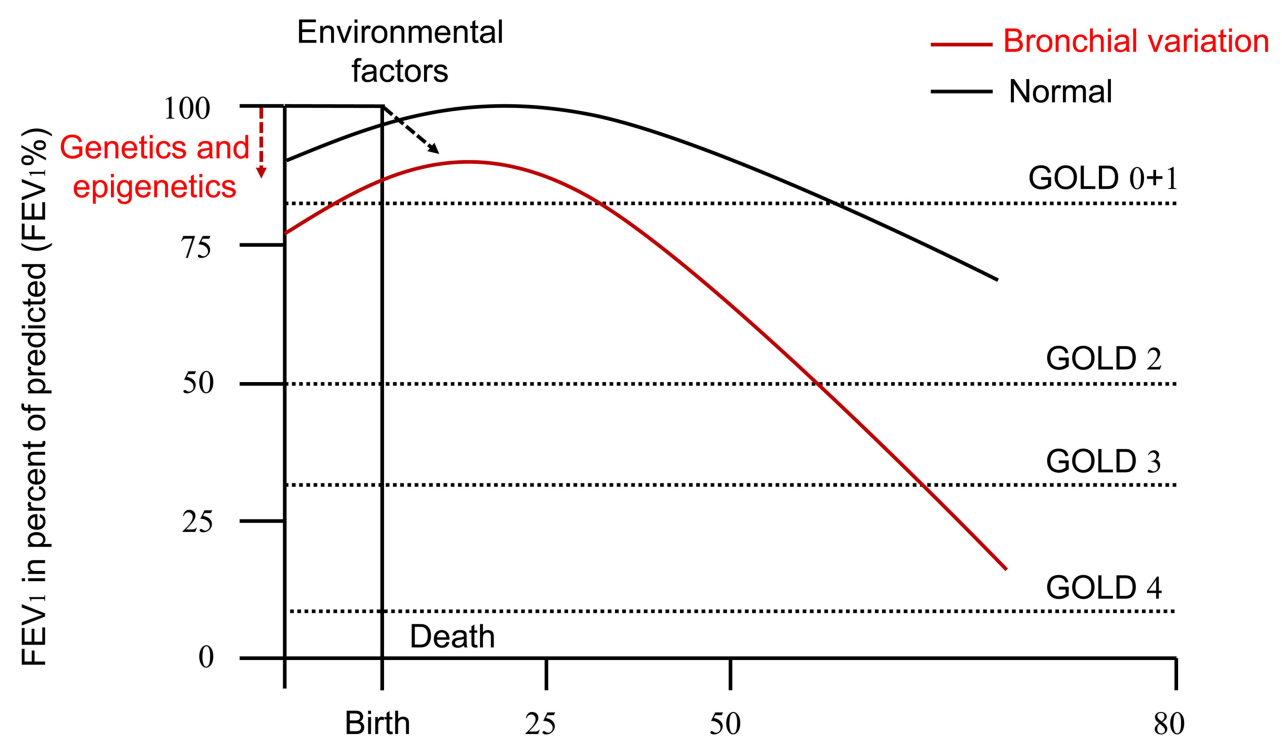

Figure I Rate of decline in FEV , with genetic and environmental factors. This downtrend of FEV , over a lifetime is determined by genetics and epigenetics before birth. Then the different curves decline in different rates dependent on organ development/repair (aging) and environmental factors (smoking and air pollutions) after birth. The lung function of people with bronchial variations is worse than that of normal people at birth. The risk of COPD is higher and earlier if environmental exposure is not taken into account.

Abbreviation: $\mathrm{FEV}_{1}$, forced expiratory volume in one second.

branch pattern and lineage of the bronchial variations result from the imbalanced development between the epithelium and the mesenchyme under genetic control mechanisms. ${ }^{24,25}$ These processes are controlled by two highly conserved families, fibroblast growth factors $(F g f s)$ and bone morphogenetic proteins (Bmps), both of which are involved epithelial and mesenchymal differentiation. FgflO is expressed in the early distal mesenchyme, whilst Bmp4 is expressed in the endodermal buds. Epithelial cells begin to grow during lung bud formation resulting in branched growth by regulating the balance between FgflO and Bmp4. Fgfl0 produced at the tip of the epithelial cells promotes endoderm proliferation and its outward movement acts to inhibit budding. This process exerts opposing effects against Bmp4 during lung bud morphogenesis. ${ }^{26}$ In Fgflo knockout mice, lung bud development is completely abolished and can be rescued by ubiquitous overexpression of Fgf10. These data indicate that the precise localized expression of FgflO is required for lung branching morphogenesis in vivo. ${ }^{27}$ In Bmp4 specific Smad knockout mice, Fgfl0 upregulates the expression of $\mathrm{Nkx2-1}$ in foregut development towards primitive lung buds (E9.25d) and exhibits an undifferentiated single lumen on E10.5-11.5d without extension. ${ }^{28}$ The opposing effects of $F g f 10$ and Bmp 4 may induce imbalances in the development of the bronchial epithelium and the mesenchyme that contributes to abnormal bronchial location and bifurcation (Figure 2). Based on these data, we hypothesize that genetic variations encoding bronchial variations can promote the development of COPD.

\section{FgflO and Bmp4 Participate in COPD and Comorbidity}

Currently, over twenty genetic loci with single nucleotide polymorphisms (SNPs) associated with COPD-related phenotypes, such as emphysema, chronic bronchitis and hypoxemia, have been demonstrated by genome-wide association studies (GWAS). ${ }^{29-31}$ ORMI, SERPING1 and $C 3$ were identified as a panel of AECOPD-specific immunomodulatory determinants. ${ }^{32}$ A clinical study found that the frequencies of Fgf10 gene SNP sites rs2973644 and rs10473352 were significantly increased in COPD patients of the Han population in North China $\left(\chi^{2}=6.021-6.213\right.$, $p<0.05){ }^{33,34} \mathrm{Bmp} 4$ is up-regulated in the airway epithelium of asymptomatic patients and COPD smokers $\left(1.0 \times 10^{-2}\right.$ vs $7.2 \times 10^{-5}$, control group: $\left.0.1 \pm 0.2\right)$. Smad signaling mediated by Bmp4 significantly disrupts the beating of cilia and secretory cell function by regulating basal cell hyperplasia and squamous cell differentiation. ${ }^{35}$ Thus, the opposing effects of $\mathrm{FgflO}$ and Bmp 4 signaling may contribute to bronchial variations and may participate in dysregulating the biology of the human airway relevant to both smoking and COPD. 

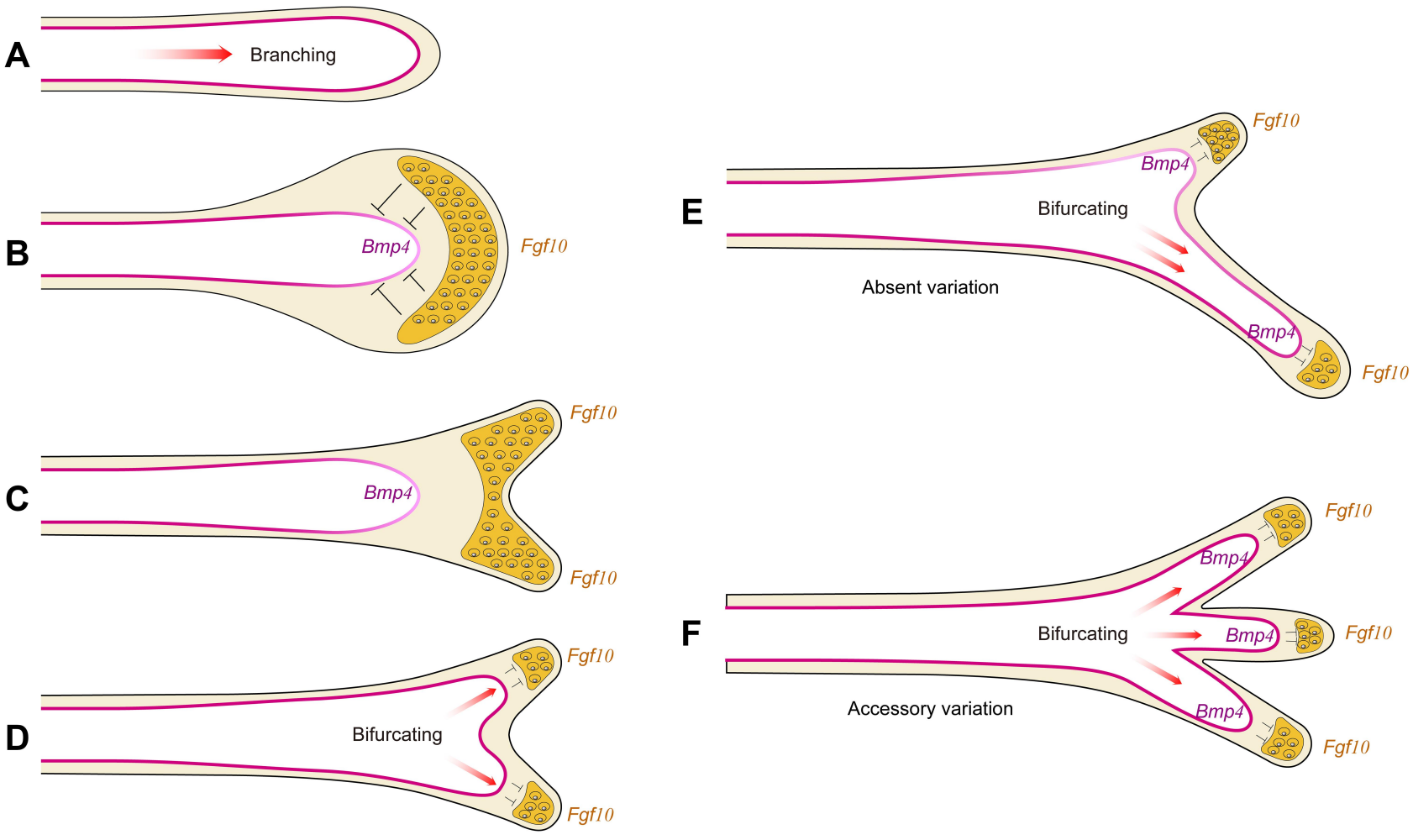

Figure $2 \mathrm{~A}$ model for the opposing effect of $\mathrm{FgflO}$ and Bmp4 in lung bud morphogenesis. An extending bud is shown schematically. Purple and yellow denote Bmp4 and FgflO expression. (A) Throughout bronchial development, Bmp4 is expressed in the epithelium and FgflO in the adjacent mesenchyme. FgflO promotes lung endoderm proliferation and migration. Bmp4 antagonizes FgflO-mediated outgrowth of lung endoderm. The balance between the expression of $\mathrm{FgflO}$ and $\mathrm{Bmp} 4$ exists during branching, keeping the normal development of bronchus. (B) As the expression of FgflO increased, distal mesenchyme has shown hypertrophic morphologically and inhibited the expression of Bmp4 in the epithelium to stop branching. (C) Restricted by the traction of the internal epithelium, the expression of Fgf 0 on both sides increased gradually, and lateral buds appeared symmetrically which represented as bifurcating. (D) Once the lung buds have been initiated, the expression of Bmp4 increased, and the expression of $\mathrm{FgflO}$ was inhibited. Epithelium grew along the distal mesenchyme towards lateral buds. The cycle of promotion of mesenchymal proliferation and outgrowth of endoderm begins again. (E) We considered the alternative hypothesis that the expression of Fgfl 0 at the tip of one lung bud increased excessively and downregulated Bmp4 expression. Then this bud formed a blind end or diverticulum with only another bud growing which was called absent variation (eg RMB or RLB in bridging bronchus). (F) When Bmp4 was more predominantly expressed than FgflO, endothelial growth was faster than mesenchyme differentiation. Then more than three buds appeared at the bifurcation which was called accessory variation (eg tracheal bronchus, accessory cardiac bronchus).

Abbreviations: Bmp4, bone morphogenetic protein 4; Fgfl0, fibroblast growth factor 10; RMB: right middle bronchus, RLB: right lower bronchus.

Fgf10 attenuates particulate matter 10 (PM10) induced airway inflammation by inhibiting apoptosis and increasing cell proliferation in bronchial epithelial (BEAS-2B) cells. ${ }^{36}$ The reduction in submucosal gland branching in Fgf10 heterozygous mice was not rescued in the adult mice. ${ }^{37}$ Knockdown of Bmp 4 by siRNA increased lipopolysaccharide and tumor necrosis factor-alpha (TNF- $\alpha$ ) induced IL-8 expression levels in human airway epithelial cells. Also, Bmp4 heterozygous mice presented with more severe lung inflammation. ${ }^{38}$ These data suggest that Fgf10 and Bmp4 may be involved in the pathogenesis of AECOPD via dysregulation of airway homeostasis.

The FgflO and Bmp4 signaling pathways are crucial for the dynamic communication between the epithelium and the mesenchyme during bronchial development (Figure 2). Epithelial-mesenchymal transition (EMT) is a process during which epithelial cells gradually transform into mesenchymal cells without epithelial function and characteristics. The reverse of this process can also occur via mesenchymal-epithelial transition (MET). Both EMT and MET can be in a balanced state during lung development. In human bronchial epithelial cells derived from patients, partial or excessive MET is found in COPD, whilst excessive EMT is detected in lung cancer, during metastatic colonization and in idiopathic pulmonary fibrosis. ${ }^{39,40}$ Fgf10 siRNA decreased GSK3 $\beta$ levels by $96 \%$ which plays an important role in EMT in breast cancer cells. ${ }^{41,42}$ However, the roles of the $F g f l 0$ and Bmp4 signaling pathways in MET and COPD remain unclear.

In a $\mathrm{Fgfl}^{-/-}$model of bronchopulmonary dysplasia, the loss of vessels was associated with an increase in poorly muscularized vessels. ${ }^{43,44}$ These abnormalities in bronchopulmonary structure increased the pulmonary 

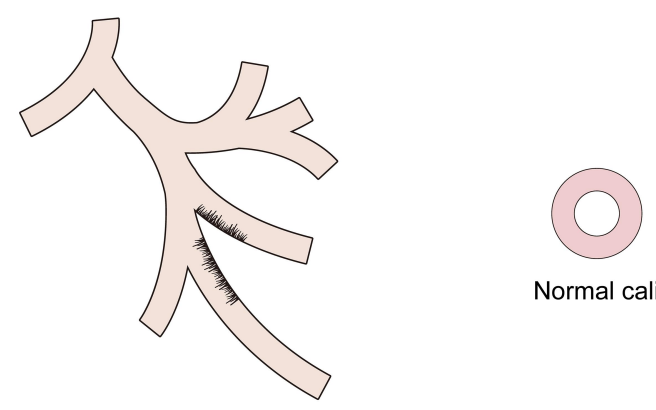

Normal caliber
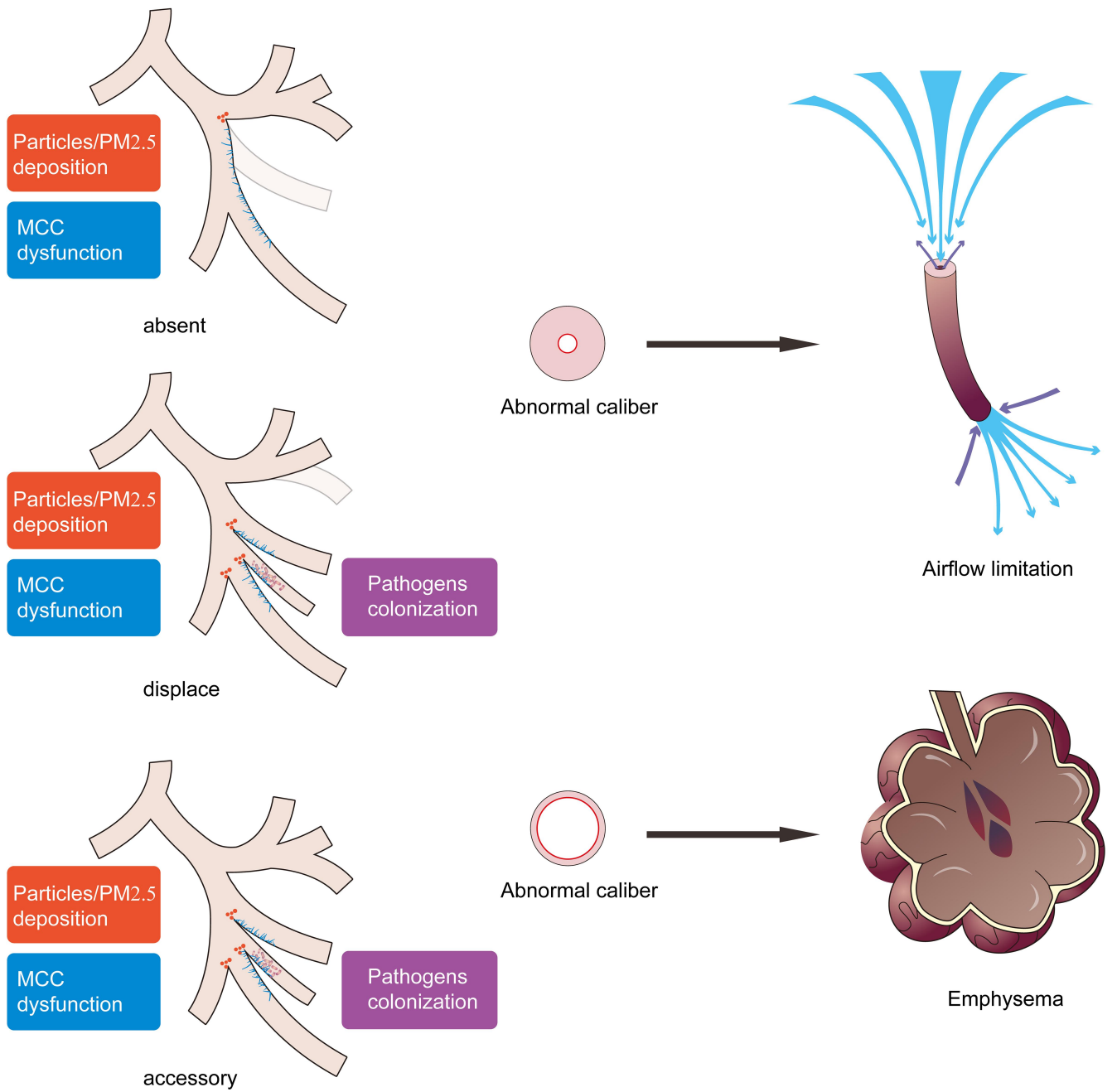

Emphysema

Figure 3 Schematic representation of bronchial variations in the development of COPD. Bronchial variations participate in the pathogenesis of COPD as anatomical determinants and promote abnormal bifurcations with more particles deposition. Abnormal variant bronchus covered cilia with movement and distribution dysfunction (MCC dysfunction) allowed more pathogens colonization. Absent or displaced bronchial variation presents bronchial wall thickening and caliber shorter, resulting in airflow limitation. Accessory or displaced bronchial variation accompanied by bronchial wall thinning and lumen enlargement results in emphysema. These are two common pathophysiological development patterns of COPD.

Abbreviations: COPD, chronic obstructive pulmonary disease; MCC, mucociliary clearance.

vascular resistance evaluated as pulmonary hypertension throughout childhood, adolescence and young adults. $^{45,46}$ The induction of oxidative stress and inflammation by the particles in the lung trigger pulmonary vascular remodeling and pulmonary capillary bed destruction in COPD with pulmonary hypertension.

\section{Conclusion}

In summary, bronchial variations may be involved in the development of COPD and contribute to complications and acute exacerbation of COPD. Studies in vitro and in vivo have shown that $F g f 10$ and Bmp4 may contribute to both bronchial variations and COPD through the 
regulation of epithelial and mesenchymal growth. These observations may have far-reaching consequences in the comprehensive evaluation of COPD via anatomical and genetic assessment. Adults with bronchial variations should be alerted to the development of COPD whether they smoke or not. For COPD patients with bronchi variations, more attention should be paid to sputum drainage and the prevention of infection. FgflO and Bmp4 may serve as heritable biomarkers to inform phenotypespecific COPD and high-risk COPD patients for lung cancer and pulmonary hypertension screening.

\section{Hypothesis}

We hypothesize that abnormal airway bifurcations may provide deposition sites for inhaled particles and MCC dysfunction to promote the colonization of pathogens and particles. Bronchial variations also characterized as abnormal airways and alveoli caliber contribute to the airflow limitations and emphysema during the pathogenesis of COPD (Figure 3).

We are planning to conduct a retrospective clinical study to evaluate the incidence of bronchial variations in COPD patients in the Chinese population, especially COPD patients with emphysema or lung cancer. Bronchial variations on $\mathrm{CT}$ can be observed for different locations and bifurcations and estimate the percentage of regional emphysema, variant bronchial lengths and inner diameters. Bronchoscopy may be performed to obtain biopsy samples along with bronchoalveolar lavage that could be used to determine the expression of key genes including FgflO and Bmp4, lower respiratory tract microbial pathogens and ciliary function. Further stratified and risk factor analyses should also be conducted.

\section{Abbreviations}

AECOPD, acute exacerbation of COPD; AI, artificial intelligence; $\mathrm{Bmp} 4$, bone morphogenetic protein 4; COPD, chronic obstructive pulmonary disease; EB-OCT, endobronchial optical coherence tomography; EMT, epithelialmesenchymal transition; $\mathrm{FEV}_{1}$, forced expiratory volume in one second; $\mathrm{FEV}_{1} \%, \mathrm{FEV}_{1}$ in percent of predicted; $\mathrm{FgflO}$, fibroblast growth factor 10; FVC, forced vital capacity; GWAS, genome-wide association studies; MCC, mucociliary clearance; MET, mesenchymal-epithelial transition; MMP-9, matrix metalloprotease-9; MPR, multi-planar reconstruction; MRI, magnetic resonance imaging; PA, pulmonary artery; $\mathrm{RB}$, right bronchus; $\mathrm{RMB}$, right middle bronchus; RLB, right lower bronchus; RSV, respiratory syncytial virus; RUL, right upper lobe; SNPs, single nucleotide polymorphisms; SSD, surface shaded display; TGF- $\beta 1$, transforming growth factor- $\beta 1$; TNF- $\alpha$, tumor necrosis factor-alpha; UL, upper lobes; VE, virtual endoscopy.

\section{Acknowledgments}

The authors acknowledge Dr. Zeng Hui Cheng from Radiology Department of Ruijin Hospital for imaging technology support. The authors would like to thank all the reviewers who participated in the review and MJEditor (www.mjeditor.com) for its linguistic assistance during the preparation of this manuscript.

\section{Author Contributions}

All authors made substantial contributions to conception and design, acquisition of data, or analysis and interpretation of data; took part in drafting the article or revising it critically for important intellectual content; agreed to submit to the current journal; gave final approval of the version to be published; and agree to be accountable for all aspects of the work.

\section{Funding}

This study was supported by National Key R\&D Program of China [grant numbers 2018YFC1311900]; Jiao Tong University School of Medicine Innovation Fund [grant numbers CBXJ201803]; Guangci Excellent Youth Plan B [grant numbers GCQN2019B03]; and Ruijin Youth NSFC Cultivation Fund [grant numbers 2019QN PY01027].

\section{Disclosure}

The authors declare no conflicts of interest in association with the present study.

\section{References}

1. GBD. Chronic Respiratory Disease Collaborators. Global, regional, and national deaths, prevalence, disability-adjusted life years, and years lived with disability for chronic obstructive pulmonary disease and asthma, 1990-2015: a systematic analysis for the Global Burden of Disease Study 2015. Lancet Respir Med. 2015;2017(5):691-706.

2. Allinson JP, Hardy R, Donaldson GC, et al. Combined impact of smoking and early-life exposures on adult lung function trajectories. Am J Respir Crit Care Med. 2017;196(8):1021-1030. doi:10.1164/ rccm.201703-0506OC

3. Tagiyeva N, Devereux G, Fielding S, et al. Outcomes of childhood asthma and wheezy bronchitis. A 50-year cohort study. Am J Respir Crit Care Med. 2016;193:23-30. doi:10.1164/rccm.201505-0870OC

4. Smith BM, Traboulsi H, Austin JHM, et al. and MESA Lung and SPIROMICS investigators. Human airway branch variation and chronic obstructive pulmonary disease. Proc Natl Acad Sci USA. 2018;115:E974-E981. doi:10.1073/pnas.1715564115 
5. Wooten C, Patel S, Cassidy L, et al. Variations of the tracheobronchial tree: anatomical and clinical significance. Clin Anat. 2014;27:1223-1233.

6. Aktas T, Aktas F, Ozmen Z, Server S, Arici A. Large-cell lung cancer originating from tracheal bronchus - A rare case. J Pak Med Assoc. 2016;66:475-476.

7. Unlu EN, Aydin LY, Bakirci S, et al. Prevalence of the accessory cardiac bronchus on multidetector computed tomography: evaluation and proposed classification. J Thorac Imaging. 2016;31:312-317.

8. Henry BM, Cheruiyot I, Wong LM, et al. The bridging bronchus: a comprehensive review of a rare, potentially life-threatening congenital airway anomaly associated with cardiovascular defects. Pediatr Pulmonol. 2019;54:1895-1904.

9. Mi WD, Zhang CS, Wang H, et al. Measurement and analysis of the tracheobronchial tree in Chinese population using computed tomography. PLoS One. 2015;10:e0123177.

10. Mclnnis MC, Weisbrod G, Schmidt H. Advanced technologies for imaging and visualization of the tracheobronchial tree: from computed tomography and MRI to virtual endoscopy. Thorac Surg Clin. 2018;28(2):127-137. doi:10.1016/j.thorsurg.2018.01.005

11. Ohno Y, Yui M, Yoshikawa T, et al. 3D oxygen-enhanced MRI at 3T MR system: comparison with thin-section CT of quantitative capability for pulmonary functional loss assessment and clinical stage classification of COPD in smokers. J Magn Reson Imaging. 2020. doi:10.1002/jmri27441

12. Ding M, Chen Y, Guan WJ, et al. Measuring airway remodeling in patients with different COPD staging using endobronchial optical coherence tomography. Chest. 2016;150(6):1281-1290. doi:10.1016/ j.chest.2016.07.033

13. Fischer AM, Varga-Szemes A, van Assen M, et al. Comparison of artificial intelligence-based fully automatic chest CT emphysema quantification to pulmonary function testing. AJR Am J Roentgenol. 2020;214:1065-1071. doi:10.2214/AJR.19.21572

14. Leung JM, Tiew PY, Aogain MM, et al. The role of acute and chronic respiratory colonization and infections in the pathogenesis of COPD. Respirology. 2017;22(4):634-650. doi:10.1111/resp.13032

15. Richmond BW, Du RH, Han W, et al. Bacterial-derived neutrophilic inflammation drives lung remodeling in a mouse model of chronic obstructive pulmonary disease. Am J Respir Cell Mol Biol. 2018;58:736-744. doi:10.1165/rcmb.2017-0329OC

16. Witten ML, Chau B, Saez E, Boitano S, Lantz RC. Early life inhalation exposure to mine tailings dust affects lung development. Toxicol Appl Pharmacol. 2019;365:124-132. doi:10.1016/j.taap.2019.01.009

17. Wang KCW, Morton JS, Davidge ST, et al. Increased heterogeneity of airway caliber in adults rats after hypoxia-induced intrauterine growth restriction. Respirology. 2017;22:1329-1335. doi:10.1111/ resp. 13071

18. Piedimonte G, Harford TJ. Effects of maternal-fetal transmission of viruses and other environmental agents on lung development. Pediatr Res. 2020;87:420-426. doi:10.1038/s41390-019-0657-4

19. Mehta J, Walsh EE, Mahadevia PJ, Falsey AR. Risk factors for respiratory syncytial virus illness among patients with chronic obstructive pulmonary disease. COPD. 2013;10(3):293-299. doi:10.3109/15412555.2012.744741

20. Wang G, Kull I, Bergstrom A, et al. Early-life risk factors for reversible and irreversible airflow limitation in young adults: findings from the BAMSE birth cohort. Thorax. 2020:thoraxjnl-2020-215884. doi:10.1136/thoraxjnl-2020-215884

21. Bui DS, Lodge CJ, Burgess JA, et al. Childhood predictors of lung function trajectories and future COPD risk: a prospective cohort study from the first to the sixth decade of life. Lancet Respir Med. 2018;6(7):535-544. doi:10.1016/S2213-2600(18)30100-0

22. Hogg JC. Pathophysiology of airflow limitation in chronic obstructive pulmonary disease. Lancet. 2004;364(9435):709-721. doi:10.1016/S0140-6736(04)16900-6
23. Martinez FD. The origins of asthma and chronic obstructive pulmonary disease in early life. Proc Am Thorac Soc. 2009;6(3):272-277. doi:10.1513/pats.200808-092RM

24. Metzger RJ, Klein OD, Martin GR, et al. The branching programme of mouse lung development. Nature. 2008;453(7196):745-750. doi:10.1038/nature07005

25. Metzger RJ, Krasnow MA. Genetic control of branching morphogenesis. Science. 1999;284:1635-1639. doi:10.1126/ science. 284.5420 .1635

26. Weaver M, Dunn NR, Hogan BL. Bmp4 and Fgf10 play opposing roles during lung bud morphogenesis. Development. 2000;127:2695-2704.

27. Volcakert T, Campbell A, Dill E, et al. Localized Fgf10 expression is not required for lung branching morphogenesis but prevents differentiation of epithelial progenitors. Development. 2013;140 (18):3731-3742. doi:10.1242/dev.096560

28. Xu B, Chen C, Chen H, et al. Smadl and its target gene Wifl coordinate BMP and Wnt signaling activities to regulate fetal lung development. Development. 2011;138:925-935. doi:10.1242/dev.062687

29. Ragland MF, Benway CJ, Lutz SM, et al. Genetic advances in Chronic Obstructive Pulmonary Disease: insights from COPDGene. Am J Respir Crit Care Med. 2019;200:677-690. doi:10.1164/ rccm.201808-1455SO

30. Kim WJ, Hoffman E, Reilly J, et al. Association of COPD candidate genes with computed tomography emphysema and airway phenotypes in severe COPD. Eur Respir J. 2011;37:39-43. doi:10.1183/ 09031936.00173009

31. Oelsner EC, Ortega VE, Smith BM, et al. A genetic risk score associated with chronic obstructive pulmonary disease susceptibility and lung structure on computed tomography. Am J Respir Crit Care Med. 2019;200:721-731. doi:10.1164/rccm.201812-2355OC

32. Shi L, Zhu B, Xu M, et al. Selection of AECOPD-specific immunomodulatory biomarkers by integrating genomics and proteomics with clinical informatics. Cell Biol Toxicol. 2018;34:109-123.

33. Danopoulos S, Shiosaki J, Al Alam D. FGF signaling in lung development and disease: human versus mouse. Front Genet. 2019;10:170. doi:10.3389/fgene. 2019.00170

34. Ren JT, Feng K, Wang P, et al. Relationship between the gene polymorphism in fibroblast growth factor-10 and susceptibility to chronic obstructive pulmonary disease 220 cases. Zhonghua Jie He He Hu Xi Za Zhi. 2013;36:935-939.

35. Zuo WL, Yang J, Strulovici-Barel Y, et al. Exaggerated BMP4 signalling alters human airway basal progenitor cell differentiation to cigarette smoking-related phenotypes. Eur Respir J. 2019;53:1702553.

36. Liu L, Xia Z, Li J, et al. Fibroblast growth factor 10 protects against particulate matter-induced airway inflammatory response through regulating inflammatory signaling and apoptosis. Am J Transl Res. 2019;11:6977-6988.

37. May AJ, Teshima THN, Noble A, et al. FGF10 is an essential regulator of tracheal submucosal gland morphogenesis. Dev Biol. 2019;451(2):158-166. doi:10.1016/j.ydbio.2019.03.017

38. Li Z, Wang J, Wang Y, et al. Bone morphogenetic protein 4 inhibits liposaccharide-induced inflammation in the airway. Eur J Immunol. 2014;44(11):3283-3294. doi:10.1002/eji.201344287

39. Jolly MK, Ward C, Eapen MS, et al. Epithelial-mesenchymal transition, a spectrum of states: role in lung development, homeostasis, and disease. Dev Dyn. 2018;247(3):346-358. doi:10.1002/dvdy.24541

40. Knight DA, Grainge CL, Stick SM, et al. Epithelial mesenchymal transition in respiratory disease: fact or Fiction. Chest. 2020;157 (6):1591-1596. doi:10.1016/j.chest.2019.12.014

41. Houghton AM. Mechanistic links between COPD and lung cancer. Nat Rev Cancer. 2013;13(4):233-245. doi:10.1038/nrc3477

42. Abolhassani A, Riazi GH, Azizi E, et al. FGF10: type III epithelial mesenchymal transition and invasion in breast cancer cell lines. J Cancer. 2014;5(7):537-547. doi:10.7150/jca.7797 
43. Chao CM, Yahya F, Moiseenko A, et al. Fgf10 deficiency is causative for lethality in a mouse model of bronchopulmonary dysplasia. J Pathol. 2017;241:91-103. doi:10.1002/path.4834

44. Chao CM, Moiseenko A, Kosanovic D, et al. Impact of Fgfl0 deficiency on pulmonary vasculature formation in a mouse model of bronchopulmonary dysplasia. Hum Mol Genet. 2019;28:1429-1444. doi:10.1093/ hmg/ddy439
45. Thebaud B, Goss KN, Laughon M, et al. Bronchopulmonary dysplasia. Nat Rev Dis Primers. 2019;5:78.

46. Sheth S, Goto L, Bhandari V, et al. Factors associated with development of early and late pulmonary hypertension in preterm infants with bronchopulmonary dysplasia. J Perinatol. 2020;40:138-148.

\section{Publish your work in this journal}

The International Journal of COPD is an international, peer-reviewed journal of therapeutics and pharmacology focusing on concise rapid reporting of clinical studies and reviews in COPD. Special focus is given to the pathophysiological processes underlying the disease, intervention programs, patient focused education, and self management protocols. This journal is indexed on PubMed Central, MedLine and CAS. The manuscript management system is completely online and includes a very quick and fair peer-review system, which is all easy to use. Visit http://www.dovepress.com/testimonials.php to read real quotes from published authors.

Submit your manuscript here: https://www.dovepress.com/international-journal-of-chronic-obstructive-pulmonary-disease-journal 